\title{
Peste des petits ruminants (PPR): A Serious Threat for Wild Life
}

Hamed Ebrahimzadeh Leylabadlo ${ }^{1}$, Hossein Samadi Kafil ${ }^{2 *}$, Mohammad Asgharzadeh ${ }^{3}$

1. Infectious Disease and Tropical Medicine Research Center, Tabriz University of Medical Sciences, Tabriz, Iran

2. Drug Applied Research Center, Tabriz University of Medical Sciences, Tabriz, Iran

3. Biotechnology Research Center, Tabriz University of Medical Sciences, Tabriz, Iran

\section{Introduction}

Peste des petits ruminants (PPR) is the most contagious and extremely infectious respiratory diseases in goats and sheep and is most common in West and Central Africa, Middle East and Southern Asia; it spreads rapidly regardless of country borders (1). A serological and virological outbreak of PPR was identified in Ilam province, Iran near the Iraqi border in 1995. Since then, despite all control measures, numerous incidents of the disease have been reported throughout the country (2). Between 1995 and 2004, vaccination of sheep and goats was performed by cell cultured rinderpest (RP) vaccine; the small ruminants started to be vaccinated from early 2005 (2). In spite of vaccination of susceptible animals and application of some containment measures, PPR spread through the whole country, infecting every province with fluctuating prevalence and continuity. The cause of this failure might be related to the fact that welldesigned control program in the country was not carried out appropriately and vaccination schedule was not covered abundantly. For instance in 2011, just over 3.5 million small ruminants received vaccine from an estimated National population of just fewer than 80 million animals (3). Some species of animal, e.g. such as gazelles, goats and sheep, that are relatively prevalent in Middle Eastern countries especially in Iran are believed to be immune to PPR infection (4). The wildlife in Iran consists of several animal species that include bears, gazelles, foxes, and also domestic animals including sheep, goats, cattle, and camels.

It is believed that PPR virus circulates in domestic ruminants and acts as a potential source of virus for wild animal species in wildlife and the role of domestic small ruminants in the spread of the disease to wild ruminants is clear. It is quite possible that in cases of pastures exchange between domestic and wild animals, the spread of PPR is facilitated between the two populations (5). In Iran, domestic and wild animals share pastures in wildlife and separation does not take place at all and animal-browsing licenses which have been issued since many years ago do not

\section{Corresponding author:}

Hossein Samadi kafil PhD. Assistant Professor

Drug Applied Research Center, Faculty of Medical Sciences Tabriz University of Medical Sciences, Tabriz, Iran Email: Kafilhs@tbzmed.ac.ir Tel: +989127184735 Fax: +984133364661

Receive date: 2016-01-10| Accept date: 2016-03-02 | Publish date: 2016-04-19

DOI: 10.7575/aiac.abcmed.16.04.02.09 
separate them from each other. Therefore, domestic animals that are close to wild ruminants are very susceptible to serious PPR outbreak.

PPR has killed lots of wild animal species in Iranian wildlife such as goats, rams, ewes (6) and wildlife will be faced by the danger of these animals getting decreased in number and thus making it difficult for carnivore animals feeding on these animals to find food .This disease could result in extinction of endangered species of wild ruminants on one hand and constraint to the global eradication of PPR on the other hand. We, therefore, suggest Iranian Department of Environment (DOE) to refuse leasing of conserved areas to ranchers which in turn would allow domestic ruminants entering them. Also, a more substantial vaccination program in domestic ruminants can protect the wildlife from a serious danger of obliteration.

\section{References}

1. Banyard AC, Parida S, Batten C, Oura C, Kwiatek O, Libeau G. Global distribution of peste des petits ruminants virus and prospects for improved diagnosis and control. Journal of general virology. 2010;91(12):2885-97.

2. Bazarghani, T. T., et al. "A review on peste des petits ruminants (PPR) with special reference to PPR in Iran." Journal of Veterinary Medicine, Series B 53.s1 (2006): 17-18.

3. Abdollahpour, G., et al. "Clinical and Para-clinical Findings of a Recent Outbreaks of Peste des Petits Ruminants in Iran." Journal of Veterinary Medicine, Series B 53.s1 (2006): 14-16.

4. Hoffmann, B., et al. "Fatalities in wild goats in Kurdistan associated with peste des petits ruminants virus." Transboundary and emerging diseases 59.2 (2012): 173-176.

5. Banyard AC, Parida S. Molecular Epidemiology of Peste des Petits Ruminants Virus. Peste des Petits Ruminants Virus: Springer; 2015. p. 69-93.

6. Availble from URL: http://www.iew.ir/1394/07/07/40634 (in Persian) 